ISSN 2236-0859

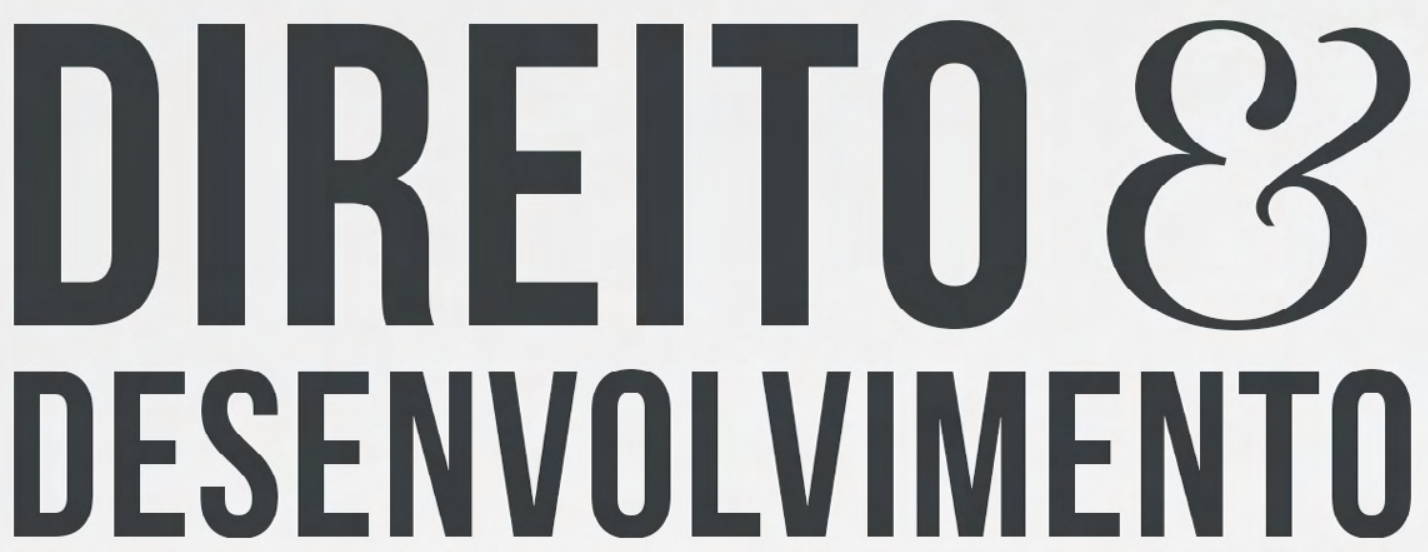

REVISTA DO PROGRAMA DE PÓS-GRADUAÇ̃̃O EM DIREITO MESTRADO EM DIREITO E DESENVOLVIMENTO SUSTENTÁVEL

O REGIME DE APROPRIACÃO SOBRE ATIVIDADE INVENTIVA NA EXECUÇÃODO CONTRATODE TRABALHO

FERNANDO ANTÔNIO DE VASCONCELOS

ROSILENE PAIVA MARINHO DE SOUSA

MARCKSON ROBERTOFERREIRA DE SOUSA 


\title{
O REGIME DE APROPRIAÇÃO SOBRE ATIVIDADE INVENTIVA NA EXECUÇÃO DO CONTRATO DE TRABALHO
}

\section{THE APPROPRIATION SCHEME ON INVENTIVE ACTIVITY IN THE EXECUTION OF THE EMPLOYMENT CONTRACT}

Recebido: 29/03/2018

Aprovado: 20/11/2018
Fernando Antônio de Vasconcelos* Rosilene Paiva Marinho de Sousa* Marckson Roberto Ferreira de Sousa***

RESUMO: Este artigo tem como escopo analisar o regime de apropriação sobre a atividade inventiva e seus reflexos frente ao desenvolvimento do sistema produtivo nacional. Para isso, busca examinar o referido regime de apropriação e seus reflexos na relação de trabalho. Aborda uma visão sobre o campo da propriedade intelectual e seus institutos jurídicos. Reflete sobre os aspectos que envolvem a execução do contrato de trabalho em face da titularidade sobrea produção inventiva considerando a Lei de Propriedade Industrial. Do ponto de vista metodológico, tratase de uma pesquisa bibliográfica e exploratória. Ao final, são apresentados possíveis limites e possibilidades da atividade inventiva e os reflexos da Consolidação das Leis Trabalhistas.

Palavras-chave: Propriedade intelectual e capital intelectual. Inovação e invenção: processos e incentivos. Indústrias regulamentadas e direito administrativo. Direito trabalhista.

\begin{abstract}
This article is scoped to analyze the appropriation regime on inventive activity and its reflexes in the face of the development of the national productive system. For this, it seeks to examine the appropriation regime and its reflexes in the working relationship. It addresses an insight into the field of intellectual property and their legal institutes. It reflects on the aspects that involve the execution of the contract of employment in the face of titularity on inventive production considering the Industrial property law. From a methodological point of view, it is a bibliographical and exploratory research. In the end, possible limits and possibilities of inventive activity and the reflections of the consolidation of labor laws are presented.
\end{abstract}

Keywords: Intellectual Property and Intellectual Capital. Innovation and Invention: Processes and Incentives. Regulated Industries and Administrative Law. Labor Law.

\section{INTRODUÇÃO}

As transformações globais ocorridas nas relações de trabalho insurgiram-se a partir da Revolução industrial do século XVIII, em face das mudanças ocorridas na maneira em que a mão de obra passava a ser utilizada pelo empregador. Com a globalização, a conjuntura internacional impulsionou em escala mundial modificações nas condições trabalhistas, em que cunhou-se uma visão econômica do trabalho como fator de produção.

\footnotetext{
*Doutor e Mestre em Direito Civil pela UFPE. Professor do Programa de Pós-Graduação em Ciências Jurídicas - PPGCJ/UFPB e do Programa de Pós-Graduação em Direito - PPGD/UNIPÊ. E-mail: fer.mengo@uol.com.br

**Advogada. Doutora e Mestra em Ciência da Informação pela Universidade Federal da Paraíba. Mestranda em Direito pelo Centro Universitário de João Pessoa - UNIPÊ. E-mail: adv.rpmsousa@gmail.com

***Doutor e Mestre em Engenharia Elétrica pela Universidade Federal da Paraíba. Acadêmico em Direito. Professor do Programa de PósGraduação em Ciência da Informação - PPGCI/UFPB e Professor do Programa de Pós-Graduação do Mestrado Profissional em Gestão nas Organizações Aprendentes - MPGOA/UFPB. E-mail: marckson.dci.ufpb@gmail.com
} 
A partir do capitalismo industrial percebeu-se o surgimento de uma grande variedade de atividades no mercado de trabalho, e consequentemente nas relações de trabalho. Neste interim, o campo da propriedade intelectual ganhou força tendo em vista o incremento no desenvolvimento econômico, científico e tecnológico oriundos da capacidade de inovação.

Surge, dessa forma, a necessidade de regular as relações de trabalho de uma nova categoria de empregado, a saber, o empregado autor de invenção. A falta de uniformidade nos institutos jurídicos da propriedade intelectual, mais especificamente nos reflexos gerados no andamento da execução do contrato de trabalho do empregado inventor, varia de acordo com a criação. Essa variação gera reflexos na execução do contrato de trabalho do empregado, pois, está intimamente relacionada ao regime de apropriação sobre o resultado do processo inventivo. Diante disso, pode-se questionar: até que ponto o trabalhador terá direito aos lucros de sua atividade intelectual sem violar o artigo 88, da Lei no 9.279/96, ao admitir a exclusividade sobre a produção inventiva ao empregador?

Para que os direitos trabalhistas do empregado autor de invenção sejam reconhecidos na execução do contrato de trabalho, paralelamente aos direitos previstos na lei de propriedade industrial - considerado o interesse social da mesma e o desenvolvimento científico, tecnológico e econômico do País - surge a hipótese de que a valorização do empregado autor de invenção contribui para maior desenvolvimento científico, tecnológico e econômico do País.

Nesse sentido, o presente artigo se propõe a examinar aspectos que envolvem a execução do contrato de trabalho levando-se em consideração a titularidade sobre a produção inventiva na Lei de Propriedade Industrial, e mais especialmente, diante da compreensão do artigo 88 do referido diploma legal. Este estudo organiza-se de modo a contextualizar uma visão sobre o campo da propriedade intelectual e os institutos jurídicos que estruturaram a mesma. Na sequência, apresenta-se, em particular o instituto da propriedade industrial e consequentemente o artigo 88, onde será abordado o regime de apropriação do autor inventor frente as invenções de serviço na execução do contrato de trabalho.

O tema proposto apresenta-se em conformidade com a temática da revista, "Estado, Trabalho e Desenvolvimento Econômico", uma vez que trata do direito ao emprego sobre o crescimento econômico e a acumulação de bens e riquezas, destacando o respeito à dignidade da pessoa humana do trabalhador, ao enfatizar não apenas a forma de trabalho humano subordinado, mas a outras formas de trabalho as quais a massa ativa trabalhadora pode se ocupar.

Quanto aos aspectos metodológicos, trata-se de uma pesquisa bibliográfica e exploratória. Bibliográfica, segundo Gil (2006), devido à necessidade de se verificar material já elaborado, constituído principalmente de livros, artigos científicos, leis, dentre outros. E exploratória, por ter como principal finalidade a necessidade de se desenvolver, esclarecer e modificar conceitos e ideias. Desta forma, considera-se exploratória na medida em que se deve buscar informações para um melhor entendimento do assunto, constituindo-se primeira etapa de uma investigação mais ampla. (GIL, 2006, p.43).

Nesse sentido, buscar-se-á analisar os instrumentos jurídicos que fundamentam a atividade inventiva, buscando mostrar como está ocorrendo à apropriação dos resultados financeiros sob a invenção de serviços. Além disso, procura apresentar possíveis limites e possibilidades da atividade inventiva e os reflexos da Consolidação das Leis Trabalhistas. 


\title{
2 O CAMPO DA PROPRIEDADE INTELECTUAL NO BRASIL
}

Para uma compreensão mais apurada, torna-se relevante ressaltar aspectos que assinalaram a regulação da propriedade intelectual, enfatizando o alcance dos institutos que a regem no âmbito nacional.

Nesse sentido, a propriedade intelectual encontra amparo no artigo $5^{\circ}$, incisos XXVII, XXVIII e XXIX da Constituição Federal (BRASIL, 1988, online): O inciso XXVII da Constituição determina que "aos autores pertence o direito exclusivo de utilização, publicação ou reprodução de suas obras, transmissível aos herdeiros pelo tempo que a lei fixar". O inciso XXVIII do texto constitucional, trata da proteção sobre "participações individuais em obras coletivas e à reprodução da imagem e voz humanas", bem como o direito de fiscalização do aproveitamento econômico das obras pelos autores, intérpretes e às respectivas representações sindicais e associativa. E, o inciso XXIX, esclarece que "[...] a lei assegurará aos inventos industriais privilégio temporário para sua utilização, bem como proteção às criações industriais [...]”.

A propriedade intelectual compreende o conjunto de direitos relativos às criações intelectuais nas diversas áreas da atividade humana. A Organização Mundial de Propriedade Intelectual/World Intellectual Property Organization (OMPI/WIPO), no entendimento de Barbosa (2010), constituiu-se em 1967, como órgão autônomo dentro do sistema das Nações Unidas, englobando as Uniões de Paris e Berna.

A WIPO apresenta como a propriedade intelectual pode ser compreendida:

Intellectual property, very broadly, means the legal rights which result from intellectual activity in the industrial, scientific, literary and artistic fields [...]. Generally speaking, intellectual property law aims at safeguarding creators and other producers of intellectual goods and services by granting them certain time-limited rights to control the use made of those productions. (WIPO, 2018, online).

Conforme Barbosa (2010, p. 10), o conceito de propriedade intelectual compreende a definição exposta pela OMPI:

\begin{abstract}
A Convenção da OMPI define como Propriedade intelectual, a soma dos direitos relativos às obras literárias, artísticas e científicas, às interpretações dos artistas intérpretes e às execuções dos artistas executantes, aos fonogramas e às emissões de radiodifusão, às invenções em todos os domínios da atividade humana, às descobertas científicas, aos desenhos e modelos industriais, às marcas industriais, comerciais e de serviço, bem como às firmas comerciais e denominações comerciais, à proteção contra a concorrência desleal e todos os outros direitos inerentes à atividade intelectual nos domínios industrial, científico, literário e artístico.
\end{abstract}

No Brasil, conforme exposto em Sousa (2016), considera-se que a propriedade intelectual se divide em dois grandes grupos, quais sejam, o direito autoral e propriedade industrial, além da proteção sui generis. Para Zanirato e Ribeiro (2007, p. 47) os direitos sui generis são aqueles denominados híbridos, por compreendem tanto direitos de propriedade industrial como de direitos autorais, tendo sido cada tipo de proteção regulamentada por lei específica.

Os direitos autorais são regulados pela Lei de Direitos Autorais, Lei no 9.610, de 19 de fevereiro de 1998, altera, atualiza e consolida a legislação sobre direitos autorais e dá outras providências (BRASIL, 1998b).

Os referidos direitos envolvem os direitos de autor sobre suas obras literárias e artísticas; direitos conexos como os direitos dos artistas-intérpretes e produtores de fonográficos; e, os que envolvem os programas de computador, regulados pela Lei no 9.609, de 19 de fevereiro de 1998 (BRASIL, 1998a). Atualmente, a lei dos direitos autorais sofreu alterações pela Lei no 
12.853, de 14 de agosto de 2013 (BRASIL, 2013), para dispor sobre a gestão coletiva de direitos autorais.

Os direitos de autor encontram guarida em sua teoria dualista originada na coexistência de dois direitos basilares, quais sejam, de natureza moral e patrimonial adotada na maioria dos países. Os direitos de natureza moral compreendem a criação do autor, tratando da manifestação de sua vontade individual, são denominados direito da personalidade, pelo seu caráter de inalienabilidade e irrenunciabilidade; já os de natureza patrimonial são os direitos de natureza econômica sobre suas criações (FRAGOSO, 2009).

Conforme expõe Basso (200o, p. 33), "[...] de uma parte, o elemento imaterial e pessoal, que se vincula à personalidade e à liberdade do autor, do criador; de outra parte, o elemento patrimonial e econômico, que é um valor suscetível de cessão e de alienação". Dessa forma, os direitos de autor em sua teoria dualista encontra amparo por estar assentada na coexistência de dois direitos básicos, a saber, o direito moral e o patrimonial.

Para Barbosa (2009, p. 762), "autor é aquele que exerce a liberdade de escolha entre alternativas de expressão". Segundo o referido autor, esse exercício de liberdade de escolha, determina a criação da obra intelectual, bem como seu criador.

Conforme especificado no inciso XXVII, do artigo $5^{\circ}$ da Constituição Federal, o autor, como criador intelectual, tem direitos exclusivos sobre suas criações. Essa condição está intimamente relacionada à personalidade do autor, não podendo ser conferida a pessoas jurídicas, sendo limitada aos direitos patrimoniais do mesmo. Essa ideia possibilita a percepção da existência da distinção entre criador intelectual e titular originário do direito sobre a criação intelectual.

Os direitos de propriedade industrial são regulados pela Lei de Propriedade Industrial, Lei no 9.279 de 14 de maio de 1996 (BRASIL, 1996), que trata de patentes de invenção, modelos de utilidade, desenhos industriais, indicações geográficas, registro de marcas e proteção de cultivares.

E, as proteções sui generis envolvem a topografia de circuito integrado e as variedades de plantas chamadas de cultivar, assim como os conhecimentos tradicionais e o acesso ao patrimônio genético (SOUSA, 2016).

No contexto da propriedade intelectual no Brasil, torna-se relevante para este artigo o estudo sobre os institutos da propriedade industrial.

\section{OS INSTITUTOS DA PRORIEDADE INDUSTRIAL}

Após realizar considerações sobre propriedade intelectual, para uma melhor compreensão, faz-se necessário um exame mais específico dos principais aspectos que envolvem a propriedade industrial.

A Lei no 9.279/96 que regula direitos e obrigações da propriedade industrial, conforme o artigo $2^{\circ}$, especifica como bens materiais protegidos a invenção, o modelo de utilidade, o desenho industrial e os sinais distintivos, (BRASIL, 1996, online):

\footnotetext{
Art. $2^{\circ}$ A proteção dos direitos relativos à propriedade industrial, considerado o seu interesse social e o desenvolvimento tecnológico e econômico do País, efetua-se mediante:

I - concessão de patentes de invenção e de modelo de utilidade;

II - concessão de registro de desenho industrial [...].
} 
A Lei da Propriedade Industrial prevê dois tipos de proteção por patentes, quais sejam, as patentes de invenção (PI) e as patentes de modelo de utilidade (MU). Por patente compreende-se o documento legal que descreve uma invenção ou modelo de utilidade do qual a invenção pode ser explorada somente com a autorização do titular da patente (SOUSA, 2016).

Para Viveiros (2010, p. 47), "[...] o que assegura na patente é a proteção que impede a terceiros a exploração do invento sem autorização do seu criador". As patentes de invenção compreendem os processos, equipamentos ou produtos inovadores que geram efeitos técnicos ou utilizações novas sem decorrência do estado da técnica.

O modelo de utilidade tem seus requisitos definidos no artigo $9^{\circ}$ da Lei $9.279 / 96$ ao determinar que (BRASIL, 1996, online):

Art. $9^{\text {o }}$ - é patenteável como modelo de utilidade o objeto de uso prático, ou parte deste, suscetível de aplicação industrial, que apresente nova forma ou disposição, envolvendo ato inventivo, que resulte em melhoria funcional no seu uso ou em sua fabricação.

Quanto ao desenho industrial, o artigo 95 da referida lei, determina que se constitui numa "[...] forma plástica ornamental de um objeto ou conjunto ornamental de linhas e cores aplicáveis a um produto apresentando resultado visual novo e original passível de fabricação industrial" (BRASIL, 1996, online). Sua distinção do modelo de utilidade se dá, especialmente, por se referir a aparência do objeto, que não é determinada pela necessidade técnica ou funcional, protegendo, assim, a forma externa do objeto e não sua função prática.

Os requisitos para a proteção da obra intelectual por meio de patente ou de registro são apresentados no artigo 8o da Lei 9.279/96, quais sejam, a novidade, atividade inventiva e a aplicação industrial. No caso do desenho industrial, os requisitos consistem em novidade, originalidade e aplicação industrial.

Ao tratar da novidade, enfatiza que a invenção e o modelo de utilidade deva ser nova, conforme o art. 11 da Lei de Propriedade Industrial, o que significa que nunca deve ter sido realizada, executada ou usada anteriormente. No entendimento de Minharro (2010, p. 39):

A invenção, o modelo de utilidade e o desenho industrial são considerados novos quando não estão compreendidos no estado da técnica, que é o acevo de todo conhecimento colocado a disposição do público, sobretudo dos especialistas, na data do depósito do pedido de patente.

No caso da atividade inventiva, deve haver na patente de invenção, conforme previsão do artigo 13 da referida lei, como condição necessária para seu reconhecimento. A atividade inventiva é um conceito subjetivo, pois, o texto da lei não a conceitua. Para o caso de modelo de utilidade, deve haver o denominado ato inventivo com previsão em seu artigo 14. Isto significa que, o modelo deve apresentar uma melhoria funcional no uso ou na fabricação em relação ao estado da técnica anterior a sua realização, para que seja considerado patenteável.

O terceiro requisito refere-se a possibilidade de aplicação industrial previsto no artigo 15, assevera que a invenção deve ser suscetível, de algum modo, de ser aplicada na indústria. Segundo o entendimento de Correia (2013, p.38), "o requisito da utilidade industrial compreende a capacidade de aplicação da tecnologia em uma atividade econômica qualquer". Em outras palavras deve-se aplicar a indústria com vista à existência de um retorno econômico.

Nesse contexto, levando-se em consideração os requisitos que definem os institutos da propriedade industrial, surge a necessidade de discutir o regime de apropriação em face da titularidade das invenções desenvolvidas pelo empregado. 


\section{OSINSTITUTOS DA PROPRIEDADEINDUSTRIALE OREGIMEDE APROPRIAÇÃO NA PRODUÇÃO INVENTIVA}

Desde o século XV, com a origem do capitalismo evidencia-se a percepção da necessidade de proteção do trabalho intelectual. No campo da propriedade intelectual, a partir do desenvolvimento científico e tecnológico que sucedeu a II Guerra Mundial, com o capitalismo industrial, percebeu-se uma crescente mudança na produção e capacidade intelectual humana, bem como, nos produtos decorrentes de sua criação.

Ao enfatizar a importância da propriedade intelectual para o crescimento do país, tornase relevante voltar a atenção para as criações intelectuais do empregado durante a vigência do contrato de trabalho. Torna-se perceptível a falta de uniformização quanto ao regime de apropriação gerada no processo de criação que varia de acordo com o tipo de invenção, refletindo diretamente incongruências estabelecidas no âmbito da sua regulação.

Neste sentido, pode-se contextualizar que se torna possível constatar incoerências dos institutos que regulam a propriedade intelectual levando-se em consideração a forma como esses direitos são colocados diante do contrato de trabalho, como por exemplo, quando o empregado não é contratado especificamente para pesquisas e invenções.

Cumpre definir, para o reconhecimento da patente ou registro no âmbito da propriedade industrial, a figura do autor/inventor e do titular originário, cuja definição implicará diretamente na titularidade do bem produzido.

A necessidade dessa definição está no reconhecimento do direito moral ou de paternidade do inventor sobre a invenção, bem como, a existência de um direito material, patrimonial ou econômico sobre a mesma.

Ao se tratar do direito moral do inventor é posto que o inventor possui o direito de ser mencionado como tal na patente, conforme determina o artigo 4 ter da Convenção de Paris (PARIS, 1883, online), "L'inventeur a le droit d'être mentionné comme tel dans le brevet". Esse direito constitui o direito de paternidade do inventor que é inalienável, imprescritível e que perpassa a expiração do prazo dos direitos intelectuais pertinentes a patente concedida.

O reconhecimento do direito moral não exige a patente, porém, conforme o direito supracitado, reconhece o direito a nominação do inventor na patente que não é obrigatório, decorrente do direito moral. Barbosa (2010, p. 354), esclarece que salvo pelo direito de menção, ao nominado que alienou o direito de pedir patente, não lhe cabe outra coisa senão o resultante do direito moral, de modo que "[...] claramente, não lhe socorre o disposto no art. 49 da Lei 9.279/96, seja para anular a patente, seja para reivindicá-la para si; sua pretensão é, exclusivamente, de obter a nominação".

Ao tratar do direito patrimonial, abre-se possibilidade da existência de um direito de titularidade em face do direito patrimonial envolvido. O artigo 6o da Lei de Propriedade Industrial esclarece que "[...] ao autor de invenção ou modelo de utilidade será assegurado o direito de obter a patente que lhe garanta a propriedade, nas condições estabelecidas nesta Lei" (BRASIL, 1996, online).

Importante observação é apresentada por Viveiros (2010), ao mencionar que a autoria determina a propriedade, e coloca que, como regra, a titularidade do invento pertence ao inventor e por força de lei ou contrato essa titularidade da propriedade dele decorrente, pode ser atribuído a outrem. É o que determina o artigo 6o, §º da Lei 9.279/96, in verbis: "A patente poderá ser requerida em nome próprio, pelos herdeiros ou sucessores do autor, pelo cessionário ou por aquele a quem a lei ou o contrato de trabalho ou de prestação de serviços determinar que pertença a titularidade" (BRASIL, 1996, online). 
A redação do artigo 6oำ $\S^{-}{ }^{\circ}$ da lei em tela, não afronta o reconhecimento da titularidade do direito moral do inventor, pois por meio do referido parágrafo, existe a presunção da existência de uma relação legal ou obrigacional entre o autor e o titular.

Ao se considerar a propriedade industrial, percebe-se que em cada um dos seus institutos jurídicos existe um regime de apropriação diferenciado tendo em vista os diferentes tipos de criação. A lei de propriedade industrial é também responsável pela regulação das marcas, que podem ter sua proteção nas formas nominativas, representando as expressões; figurativa, que regula apenas a figura sem letras e números; mista, pela conjunção de nomes e figuras; e, formas plásticas distintivas, que são as tridimensionais. Como requisito para o seu reconhecimento é exigida a distintividade.

O regime de apropriação sobre a criação das marcas é um caso peculiar em que se deve levar em consideração sua função. Segundo o entendimento de Prado (2011), se a sua função for para assinalar produtos ou serviços para diferenciá-los no mercado, a proteção será realizada pela lei de propriedade industrial.

Entretanto, se estiver se tratando de função apenas de forma, a proteção ocorre através da lei de direitos autorais, passível de apropriação pelo empregado, caso não haja termo de cessão de direitos ao empregador, de modo que esse termo não restringe a aplicação para uso comercial. Desse modo, a lei de propriedade industrial não trata expressamente sobre o regime de apropriação das marcas, apenas impõe condições de propriedade pelo registro validamente expedido.

A cultivar pode ser entendida de acordo com o artigo 3º, inciso V, da Lei no 9.456/97 que dispõe sobre cultivar, como "variedade de qualquer gênero ou espécie vegetal superior que seja claramente distinguível de outras cultivares conhecidas por margem mínima de descritores" (BRASIL, 1997, online).

No caso das cultivares há uma previsão nesta lei, no artigo $5^{\circ}$, $§ 3^{\circ}$, em que a sua obtenção em decorrência de contrato de trabalho, deverá indicar o nome de todos os melhoristas empregados (autor da criação protegida). O regime de apropriação de cultivares é próximo ao previsto na lei de propriedade industrial, porém, não há disposição sobre a apropriação exclusiva pelo empregado, possivelmente passível de proteção, dispondo também sobre a apropriação pelo empregador ou por ambos.

A topografia dos circuitos integrados é compreendida como “[...] imagens relacionadas, construídas ou codificadas sob qualquer meio ou forma, que represente a configuração tridimensional das camadas que compõem um circuito integrado" (PRADO, 2011, p. 60).

O direito de nominação referente a topografia, não tem previsão expressa na lei, mas aplica-se a previsão do artigo 5º, inciso XXIX da Constituição Federal. A Lei no 11.484/o7 (BRASIL, 2007, online), que regula a topografia de circuitos integrados, prevê expressamente o regime de apropriação para o empregador e empregado, mas não prevê a apropriação por ambos, como ocorre na lei de propriedade industrial e na lei de cultivar.

Pelo empregador, de acordo com o artigo 28 da referida lei, ocorre a inclusão da apropriação, mesmo que o empregado desenvolva a topografia sem ter sido em decorrência do contrato de trabalho, mas que utilize instalações e equipamentos do empregador. Este caso gera de qualquer forma, insegurança jurídica, passível de resolução em juízo, pois retira totalmente a possibilidade de titularidade do empregado. E, pelo empregado, sem relação com contrato e sem relação com o uso de equipamentos e instalações do empregador.

Quanto ao Software, embora a Lei de Direito Autoral preveja sua proteção, regula-se por lei específica, a saber, a Lei no $9.609 / 98$ que dispõe sobre programa de computador (BRASIL, 1998a, online). Conforme ocorre com a regulação do regime de apropriação da topografia, o regime de apropriação tem previsão para o empregador e empregado. 
A apropriação pelo empregado, na lei de programa de computador está previsto no $\S 2^{\circ}$ do artigo $4^{\circ}$, para o caso em que o software tenha sido desenvolvido sem relação com o contrato de trabalho e sem utilização de recursos do empregador. Nessa situação não há previsão de apropriação conjunta entre empregador e empregado, como ocorre na invenção, desenho industrial e cultivar.

O capítulo XIV da Lei no 9.279/96 (BRASIL, 1996, online), regula o regime de apropriação sobre "invenção e do modelo de utilidade realizado por empregado ou prestador de serviço", explorado na sequência.

\section{REGIME DE APROPRIAÇÃO E REFLEXOS DA CONSOLIDAÇÃO DAS LEIS TRABALHISTAS}

O desenvolvimento econômico de um país está atrelado aos incentivos e investimentos destinados a pesquisa em ciência, tecnologia e inovação. Essa visão teve seu grau de relevância ampliado a partir do processo de globalização, ao apresentar uma visão econômica do trabalho como fator de produção. Surge então a necessidade de se regular as relações de trabalho do empregado 'autor de invenção', considerando a discussão sobre a apropriação dos resultados financeiros oriundos da invenção de serviços. O regime de apropriação sobre invenção e do modelo de utilidade realizado por empregado ou prestador de serviço, está regulado nos artigos 88 a 93, do capítulo XIV da Lei no 9.279/96.

Como já mencionado, o ponto de partida para a análise do regime de apropriação sobre a atividade inventiva se dá em face de uma relevante distinção diante do que se denomina criador e titular originário.

A necessidade dessa definição está no reconhecimento do direito moral ou de paternidade do inventor sobre a invenção, bem como, a existência de um direito material, patrimonial ou econômico sobre a mesma, assim como ocorre com o direito autoral. Com base nesse entendimento, pode-se dizer que os direitos do inventor se equiparam ao direito do autor de obras literárias e artísticas. Correia (2013, p. 28) destaca que "[...] a tutela do direito exclusivo do autor de publicar a obra literária, ou de produzir a obra artística, corresponde à do direito do inventor de usar e explorar a invenção de modo exclusivo".

Nesse sentido, o regime de apropriação, conforme exposto em Prado (2011), pode ocorrer pelo empregador, pelo empregado ou por ambos e ocorre diante de três espécies de invenção consideradas pela lei em comento, quais sejam, a invenção de serviço, a invenção mista e a invenção livre.

A invenção mista ocorre por parte de ambos (empregador e empregado), caso em que trata especificamente, da previsão do artigo 91 da Lei no 9.279/96, ao estabelecer que a propriedade "[...] será comum, em partes iguais, quando resultar da contribuição pessoal do empregado e de recursos, dados, meios, materiais, instalações ou equipamentos do empregador" (BRASIL, 1996, online).

A invenção livre tem seu fundamento no artigo 90 da mesma Lei, caso em que a propriedade exclusiva da invenção ou modelo de utilidade pertence ao empregado, desde que não tenha vínculo do contrato de trabalho e que não decorra de meios e materiais do empregador. O artigo 90 determina que "[...] Pertencerá exclusivamente ao empregado a invenção ou o modelo de utilidade por ele desenvolvido, desde que desvinculado do contrato de trabalho e não decorrente da utilização de recursos, meios, dados, materiais, instalações ou equipamentos do empregador" (BRASIL, 1996, online). 
A invenção de serviço com previsão no artigo 88 da Lei em comento realiza-se em cumprimento a dever contratual estabelecido na formação do contrato de trabalho. Desse modo, excepcionalmente, a titularidade pode ser atribuída também a pessoas jurídicas, por pertencer ao empregador à invenção em decorrência do contrato de trabalho.

Importante ressaltar, em particular, que o estudo do referido artigo trata especificamente da exclusividade do empregador sobre a invenção e do modelo de utilidade em decorrência de contrato de trabalho.

Determina o artigo 88 (BRASIL, 1996, online), que:

Art. 88. A invenção e o modelo de utilidade pertencem exclusivamente ao empregador quando decorrerem de contrato de trabalho cuja execução ocorra no Brasil e que tenha por objeto a pesquisa ou a atividade inventiva, ou resulte esta da natureza dos serviços para os quais foi o empregado contratado.

A invenção de serviço pode ser compreendida como aquelas criadas pelo empregado, mas que pertencem ao empregador por decorrência de contrato de trabalho. Apresenta dois elementos importantes os quais a caracteriza, sendo o primeiro, o objeto do contrato que é a pesquisa ou atividade inventiva; e, segundo, o resultado dessa atividade que se trata da obtenção da invenção que advém do ato inventivo.

Nesse sentido, Correia (2013, p. 74) afirma que as invenções de serviços serão reconhecidas “[...] pela própria natureza da atividade, que será, necessariamente, de investigação, pesquisa, desenvolvimento de estudos, análises ou trabalhos que possam conduzir, eventualmente, à invenção".

No artigo 88 ainda está previsto a titularidade do empregador sobre a invenção e atividade inventiva e, no que couber ao desenho industrial, que resulte da natureza dos serviços para os quais foi o empregado contratado. Para Viveiros (2010, p. 64), as invenções de serviços estão diretamente ligadas as "[...] que são realizadas pelo empregado no cumprimento de suas funções (inventivas) expressas no contrato de emprego".

Torna-se enfático o que essa determinação legalmente impõe, diante de que essa espécie de invenção está relacionada ao resultado da atividade para o qual o empregado foi contratado, e por esse motivo o $§ 1^{\circ}$ do artigo em comento, determina que a retribuição pela invenção de serviço limita-se ao salário ajustado, salvo disposição contratual expressa. Isso significa que a legislação brasileira isentou o empregador de pagar qualquer remuneração adicional por inventos de serviço, conferindo a este uma mera faculdade.

Merece atenção a previsão do referido $\S 1^{\circ}$, porquanto, onde é possível perceber que a complexidade das normas de propriedade intelectual muitas vezes exige a inserção de outras, para proteção de valores que fogem aos limites de sua atuação. Nesse contexto, a propriedade industrial sofre restrições diante de outros valores constitucionais e infraconstitucionais, os quais muitas vezes suscitam incoerências, principalmente ao tratar do empregado autor de invenção.

Essa afirmação baseia-se na ideia de que, a propriedade intelectual de uma forma geral, na medida em que não pode servir de limitação ao desenvolvimento econômico, também não pode servir de obstáculo aos valores sociais do trabalho, visto que o artigo 170 da Constituição Federal deixa claro que a ordem econômica brasileira funda-se na valorização do trabalho humano (BRASIL, 1988).

Baracho e Souza (2011, p. 31) destacam que em relação às reformas econômicas, a Constituição de 1988 "[...] inaugura um novo momento na história constitucional brasileira, que conclama a construção de institutos jurídicos condutores da estabilização econômica.”. 
Pode-se observar ainda na orbita do $\S 1^{\circ}$, que o empregador, na maioria das vezes, com o intuito de obter lucro maior, não paga ao empregado, além do que a lei estipulou, no caso apenas o salário ajustado, deixando o empregado à margem dos ganhos obtidos com seu invento.

Essa questão vai além da relação de trabalho e perpassa aspectos que envolvem a relação de trabalho do empregado, abrangendo também as suas condições de bem-estar. Conforme Cecato e Rupert (2009), a relação que envolve empregador e empregado sofre os efeitos da intensificação da globalização no mundo do trabalho. Desses efeitos, surge a ameaça de que o empregado possa se submeter pelas circunstâncias, a condições de emprego e trabalhos degradantes em troca da manutenção do emprego.

Desta forma, afirmam ainda Cecato e Rupert (2009, p. 97), que "[...] o direito ao emprego, assim como os demais direitos sociais fundamentais devem ter primazia sobre o crescimento econômico e a acumulação de bens e riquezas".

O que se evidencia na relação estabelecida entre empregador e empregado está intimamente ligado a uma grande diversidade nas relações de trabalho advindas com todos os avanços da globalização. Nesse sentido, Nunes e Dantas (2012, p. 76), afirmam que:

A heterogeneidade das relações de trabalho e o desemprego passaram a exigir uma reestruturação do Direito Laboral, de modo que seja conferida uma proteção adequada e mensurada ao trabalho, e garantido o respeito à dignidade da pessoa do trabalhador.

Acioli e Andrade (2015), corroborando com o pensamento de Nunes e Dantas (2012), esclarecem que na atualidade há uma necessidade de dirigir o sistema jurídico trabalhista não apenas de maneira relativa a forma de trabalho humano subordinado, que deixa à margem todas as outras demais formas de trabalho capazes de serem ocupadas pela massa ativa trabalhadora.

Os referidos autores destacam a importância do princípio da proteção social, ao afirmarem que "[...] é necessário fazer atuar a proteção do hipossuficiente para além das relações de emprego para aplacar a desigualdade econômica, técnica, jurídica e social encabrestada pelo sujeito de dominação econômica ao proletariado desde o limiar do sistema capitalista" (ACIOLI; ANDRADE, 2015, p. 55).

Newton e Oliveira (2010, p. 289) esclarecem que o "[...] investimento em capital humano desempenha um papel importante na trajetória laboral dos trabalhadores". Diante das condições em que se apresenta o empregado autor de invenção pode-se verificar a necessidade de um olhar jurídico mais detalhista sobre o assunto tendo em vista que o referido empregado detém o conhecimento para a inovação, tornando-se passível de contribuição para um maior desenvolvimento científico, tecnológico e econômico do País.

Como exemplo das controvérsias entre empregado autor de invenção decorrente de contrato de trabalho e o empregador, destacando-se pelo grau de repercussão, encontrase o caso de Nélio José Nicolai, inventor do BINA, aparelho de identificação de chamadas telefônicas, incorporado como sistema funcional da grande maioria dos telefones, que nunca recebeu royalties, pela sua invenção.

Algumas sentenças em favor de Nicolai já foram proferidas, como as que obrigam a Americel - Claro, e por ultimo a Vivo, entre 20 empresas de telefonia a pagar royalties. Neste último caso, a decisão da 2. - Vara Cível de Brasília determina que a Vivo pague em juízo 25\% do valor do serviço de identificação de chamada para cada usuário e em cada aparelho.

Ainda assim, Segundo o referido autor, algumas das ações transitadas em julgado desde 1998, ainda se encontram em fase de liquidação. Nicolai, ainda não recebeu nenhum 
valor correspondente ao seu direito sobre sua autoria de invenção, percebendo-se uma longa disputa judicial que a mais de vinte anos vem acontecendo.

Conforme Rabello (2012, online), Nélio é autor de outros quatro inventos utilizados mundialmente pela telefonia, quais sejam, o Salto (sinalização sonora ligação, que outra chamada está na linha), o sistema de Mensagens de Instituições Financeiras para Celular, operações bancárias via celular; o Bina-Lo, que registra chamadas perdidas; e o telefone fixo celular.

Desse modo compreende-se que a lei de propriedade intelectual ao voltar-se mais claramente ao crescimento econômico do país, põe em segundo plano aquele que é o alicerce desse crescimento - o empregado.

\section{LIMITES E POSSIBILIDADES DA ATIVIDADE INVENTIVA EM FACE DA CONSOLIDAÇÃO DAS LEIS TRABALHISTAS}

Questão interessante envolve a competência para tratar sobre os entraves advindos da execução de contrato de trabalho do empregado autor de invenção. Sabe-se que a primeira norma que buscou regular o regime de apropriação de um invento foi o artigo 454 da CLT (BRASIL, 1943), atualmente revogado pelas sucessivas leis que regularam a propriedade industrial desde então.

Neste aspecto, é suscitada por estudiosos do assunto, a questão da propriedade industrial, como lei geral, ter revogado o referido artigo da CLT, considerada lei especial, que embora tenha ocorrido, a competência para julgar os casos que envolvem as criações no âmbito da execução do contrato de trabalho é da Justiça do Trabalho.

Outro agravante que se pode destacar está na previsão do artigo 89, parágrafo único da Lei de Propriedade Industrial, ao estabelecer que a participação nos ganhos econômicos não se incorpora, a qualquer título, ao salário do empregado (BRASIL, 1996). A CLT estabelecia no seu artigo 457, § 1ำ, que "[...] integram o salário não só a importância fixa estipulada, como também as comissões, percentagens, gratificações ajustadas, diárias para viagens e abonos pagos pelo empregador" (BRASIL, 1943, online). Com a medida provisória oㅜ 8o8, de 2017 (BRASIL, 2017, online), no referido parágrafo passou a constar que "[...] integram o salário a importância fixa estipulada, as gratificações legais e de função e as comissões pagas pelo empregador", restringindo ainda mais as incorporações ao salário.

Além disso, o artigo $7^{\circ}$, inciso XI da Constituição Federal, assegura ao trabalhador a participação nos lucros e nos resultados da empresa. $O$ empregado autor de invenção, por sua contribuição pode interferir de maneira expressiva nos resultados obtidos. Nesse sentido, observa-se a existência de ambiguidades sobre quais direitos podem ser estipulados para o empregado, para que ele não seja prejudicado.

Diante desse quadro, torna-se perceptível a existência de incoerências da propriedade intelectual, na execução do contrato de trabalho em face da titularidade sobre a produção inventiva que se reflete diretamente na apropriação dos resultados financeiros do trabalho.

Ainda na análise do artigo 88 da Lei de Propriedade Industrial, especificamente, compreende-se a necessidade de se definir quem é o empregado para a CLT e como o mesmo passa a ser definido nessa relação estabelecida pelo artigo 88 da Lei de propriedade industrial. $\mathrm{O}$ artigo $3^{\circ}$ da CLT define o empregado como "pessoa física que presta serviços de natureza não eventual a empregador, sob a dependência deste e mediante salário", e ainda mais pode ser percebido no parágrafo único desse artigo "[...] Não haverá distinções relativas à espécie 
de emprego e à condição de trabalhador, nem entre o trabalho intelectual, técnico e manual." (BRASIL, 1943, online).

Pode-se argumentar que uma das incoerências estabelecidas está em definir quem é o empregado nesta relação, diante do posicionamento de que, compreender o empregado como autor de invenção torna-se complexo, em virtude da Lei de Propriedade Industrial não o definir explicitamente por falta de critério específico, como exemplo, por não trazer em seu texto o conceito de invenção.

Não Há um conceito de invenção na lei e nem na doutrina, porém, a invenção pode ser compreendida como tudo aquilo que é inventado e que pode ser explorado no âmbito econômico. Compreende-se que o termo invenção pode ser interpretado de várias formas. Nesse sentido, o Instituto Nacional de Propriedade Intelectual (INPI, 2014, p. 2), especifica que "uma invenção pode ser definida como uma nova solução para um problema técnico específico, dentro de um determinado campo tecnológico".

A previsão legal do artigo 218, $\$ 3^{\circ}$ da Constituição Federal conceitua o trabalhador inovador, por determinar que se conceda meios e condições de trabalho aos que se ocupem das áreas de ciência, pesquisa e tecnologia (BRASIL, 1988, online).

A invenção possuidora de características que possibilitem a sua utilização no mercado, com objetivo de gerar desenvolvimento econômico, torna-se inovação. O trabalho voltado para a inovação sugere uma categoria de trabalhador que está diretamente envolvido com pesquisa e criação. Nessa visão, remanesce como parâmetros para definição, a natureza jurídica da invenção que conforme já mencionado, varia conforme o tipo, em cada instituto jurídico que trata da propriedade intelectual.

Outrossim, existem discussões que abrangem o critério de subordinação na definição que envolve o empregado autor de invenção. Subordinação, para Abbagnano (1998, p. 924), compreende, "(lat.Subordinatio, in. Subordination; it Subordinazione). Relação entre dois conceitos: um deles (o subordinado) faz parte da extensão do outro (o sobre-ordenado)".

Pode-se perceber que as características que definem o empregado, a saber, pessoalidade, onerosidade, continuidade, exclusividade e subordinação, também não se adequam em sua totalidade. Quando se tratar do requisito da subordinação, diante do grau de conhecimento profissional do empregado, do qual o empregador não é possuidor, pode-se falar em subordinação técnica invertida, compreendendo-a como critério de subordinação insuficiente. Conforme Ermida Uriarte e Hernández Álvarez (2003, p.276),

[...] pues no necesariamente el trabajador jurídicamente dependiente debería ser un hiposuficiente social o económico sujeto a tutela—, su imprecisión técnica — por cuanto el trabajador subordinado podría tener una alta calificación profesional e independencia técnica, llegándose a hablar, en ocasiones, de subordinación técnica invertida [...].

Seguindo esse entendimento, se o poder de direção do empregador não ocorre, não há em que se falar de empregado pela falta do requisito da subordinação.

No entendimento de Minharro (2010, p. 164), a atividade exercida pelo empregado para a criação intelectual não pode ser considerada trabalho comum, visto que resulta não apenas da força de trabalho, "[...] mas sim de um conjunto de fatores que envolvem aptidão pessoal, experiência, inteligência, sensibilidade [...]”. Nesse contexto, torna-se visível que o poder diretivo do empregador se utilizado de forma interventiva nas criações de serviço, poderá inibir a criatividade do empregado.

Consequentemente, sugere o autor supracitado que o poder diretivo deve ser posto em prática de forma diferenciada, de modo que a subordinação possa ser colocada de forma relativa em que o empregado possa direcionar sua força de trabalho. 
Duas são as formas de resolver os entraves advindos desta situação. As querelas são resolvidas no âmbito administrativo conforme previsão do artigo 50 da Lei de Propriedade Industrial, e serão decididas pelo presidente do INPI, sobre a nulidade ou não da patente. No âmbito judicial, nos casos que envolvem a execução do contrato de trabalho, a definição ficou estabelecida na previsão da Emenda Constitucional no 45 de 2004, em face dos princípios que as regem, sendo o direito do trabalho voltado para as questões que versam sobre contrato de trabalho, resta definida a competência da Justiça do Trabalho.

Percebe-se que de modo geral, na execução de contrato de trabalho, muitas vezes o empregador como parte mais favorecida financeiramente, e com objetivo de obtenção maior de lucro, acaba por utilizar a força de trabalho do seu empregado para atingir objetivo de maiores lucros. Desse modo em muitas ocasiões firmam contratos com conteúdos diversos ao estipulado por lei, e uma série de outras decisões que põem em questão a execução desses contratos, que precisam ter critérios melhor definidos em face dessa relação.

Torna-se extremamente importante uma reflexão sobre como o empregado autor de invenção terá direito aos dividendos de sua atividade intelectual sem violação do artigo 88 da Lei de Propriedade Industrial, ao envolver questões que versem sobre prestação de serviço sem vinculo empregatício, contrato de prestação de serviço em regime de autonomia, terceirizados, eventuais, avulsos. Outras formas podem ainda ser percebidas, conforme expõe Correia (2013, p.101), sobre "[...] trabalhador não contratado para fins inventivos, cria um produto ou solução inovadora aos negócios empresariais e seu empregador faz uso de sua criação com redução de tempo e custo, auferindo, portanto, vantagens econômicas".

Diante dessa discussão, percebe-se a necessidade de valorização do empregado autor de invenção para o efetivo desenvolvimento científico, tecnológico e econômico do País, uma vez que o estimulo pode favorecer a criatividade, levando a promoção de aumento de produtividade, redução de custos e aumento das margens de lucros.

\section{CONSIDERAÇÕES FINAIS}

Diante do contexto abordado sobre a relação de trabalho que envolve o autor de invenção - empregado, e o titular originário na figura do empregador, torna-se possível observar que os direitos trabalhistas destes empregados devem ser reconhecidos na execução do contrato de trabalho, paralelamente aos direitos previstos na lei de propriedade industrial, considerado o interesse social da empresa.

Faz-se relevante levar em consideração que o desenvolvimento econômico do país depende em parte da mão-de-obra do trabalhador, de modo que a valorização do empregado, e em particular no caso em estudo, do autor de invenção, contribui para o maior desenvolvimento científico, tecnológico e econômico do país.

Outra questão que deve ser levada em consideração refere-se a necessidade de que a propriedade intelectual tem que redimensionar aspectos que envolvam a titularidade da atividade inventiva, nos seus institutos que variam de acordo com a criação. Essa variação dos institutos e em particular dos que envolvem a propriedade industrial, deve considerar o princípio da proteção social, de forma que possa amparar todas as formas de relação de trabalho, bem como os fundamentos da ordem econômica, previsto no artigo 170 da Constituição Federal, ao estabelecer como um de seus fundamentos a valorização do trabalho humano.

Desse modo, a necessidade de não haver uma dissociação das normas de direito do trabalho e de propriedade industrial para regulação do contrato de trabalho do empregado inventor, ou pelo menos um realinhamento de proposituras, pode vir a possibilitar o incentivo 
a promoção da dignidade da pessoa humana do trabalhador e do desenvolvimento social e econômico.

\section{REFERÊNCIAS}

ABBAGNANO, Nicola. Dicionário de Filosofia. 2. Ed. São Paulo: Martins Fontes, 1998.

ACIOLI, José Adelmy da Silva; ANDRADE, Everaldo Gaspar Lopes. Fundamentos do Princípio da Proteção Social: As alternativas para sua reconfiguração, a partir da economia social e solidária, de uma renda universal garantida e das teorias dos movimentos sociais. Revista Acadêmica - Faculdade de Direito do Recife, v. 87, n. 1, jan/jun, 2015. Disponível em: <http:// www.repositorios.ufpe.br/revistas/index.php/ACADEMICA/article/view/1550/1212>. Acesso em: 24 mar. 2018.

BARACHO, Hertha Urquiza; SOUZA, Jacyara Farias. As Reformas Econômicas no Estado Brasileiro Pós-Constituição Federal de 1988: uma proposta desenvolvimentista. Revista Direito e Desenvolvimento. a. 2, n. 3, jan./jun., 2011. Disponível em: <https://periodicos. unipe.br/index.php/direitoedesenvolvimento/article/view/164/147>. Acesso em: 24 mar. 2018.

BARBOSA, Denis Borges. Uma Introdução à Propriedade Intelectual. Rio de Janeiro: Lumen Juris, 2010.

BARBOSA, Denis Borges. A Propriedade Intelectual no Século XXI: Estudos de direito. Rio de Janeiro: Lumen Juris, 2009.

BASSO, Maristela. O direito internacional da propriedade intelectual. Porto Alegre: Livraria do advogado, 2000.

BRASIL. CONSTITUIÇÃO DA REPÚBLICA FEDERATIVA DO BRASIL (1988). Brasília, DF: Senado Federal: Centro Gráfico, 1988. Disponível em: <http://www.planalto.gov.br/ ccivil_03/ Constituicao/ConstituicaoCompilado.htm>. Acesso em: 20 mar. 2018.

. Decreto-Lei no 5.452 de $1^{\circ}$ de maio de 1943. Aprova a Consolidação das Leis do Trabalho. Diário Oficial da União. Brasília, og de agosto de 1943. Disponível em:

<http://www.planalto.gov.br/ccivil_03/decreto-lei/Del5452compilado.htm>. Acesso em: 20 mar. 2018.

. Medida Provisória no 808, de 14 de novembro de 2017. Altera a Consolidação das Leis do Trabalho - CLT, aprovada pelo Decreto-lei oㅜ 5,452, de $1^{\circ}$ de maio de 1943 . Diário Oficial da União. Brasília, 14 de novembro de 2017. Disponível em: <http://www.planalto.gov.br/ ccivil_03/_Ato2015-2018/2017/Mpv/mpv8o8.htm\#art1>. Acesso em: 24 mar. 2018.

. Lei no 9.456, de 25 de abril de 1997. Institui a Lei de Proteção de Cultivares e dá outras providências. Diário Oficial da União. Brasília, o8 de abril de 1997. Disponível em: <http:// www.planalto.gov.br/ccivil_03/leis/L9456.htm>. Acesso em: 20 mar. 2018. 
. Lei 9.609, de 19 de fevereiro de 1998. Dispõe sobre a proteção da propriedade intelectual de programas de computador, sua comercialização no país, e dá outras providências. Diário Oficial da União. Brasília, 20 fev. 1998. Disponível em: <http://www.planalto.gov.br/ccivil_03/ Leis/L96og.htm>. Acesso em: 23 mar. 2018.

. Lei 9.610, de 19 de fevereiro de 1998. Altera, atualiza e consolida a legislação sobre direitos autorais e dá outras providências. Diário Oficial da União. Brasília, 20 fev. 1998. Disponível em: <http://www.planalto.gov.br/ccivil_03/leis/L9610.htm>. Acesso em: 23 mar. 2018.

Lei no 11.484 de 31 de maio de 2007. Dispõe sobre os incentivos às indústrias de equipamentos para TV Digital e de componentes eletrônicos semicondutores e sobre a proteção à propriedade intelectual das topografias de circuitos integrados, instituindo o Programa de Apoio ao Desenvolvimento Tecnológico da Indústria de Semicondutores - PADIS e o Programa de Apoio ao Desenvolvimento Tecnológico da Indústria de Equipamentos para a TV Digital - PATVD. Disponível em: <http://www.planalto.gov.br/ccivil_03/_ato2007-2010/2007/lei/ L11484compilado.htm>. Acesso em: 23 mar. 2018.

Lei 12.853, de 14 de agosto de 2013. Altera os arts. 5º, 68, 97, 98, 99 e 100, acrescenta arts. 98-A, 98-B, 98-C, 99-A, 99-B, 100-A, 100-B e 109-A e revoga o art. 94 da Lei no 9.610, de 19 de fevereiro de 1998, para dispor sobre a gestão coletiva de direitos autorais, e dá outras providências. Diário Oficial da União. Brasília, 15 ago. 2013. Disponível em: <http://www. planalto.gov.br/ccivil_03/_Ato2011-2014/2013/Lei/L12853.htm>. Acesso em: 23 mar. 2018.

Lei 9.279, de 14 de maio de 1996. Regula direitos e obrigações relativos à propriedade industrial. Diário Oficial da União. Brasília, 15 de maio 1996. Disponível em: <http://www. planalto.gov.br/ccivil_03/Leis/L9279.htm>. Acesso em: 23 mar. 2018.

CECATO, Maria Aurea Baroni; RUPERT; Maria Belén Cardona. Direito Social na União Européia e Mercosul. João Pessoa, 2009.

CORREIA, Silvia. Os Inventos no Cenário Empresarial: Aspectos trabalhistas e econômicos. São Paulo: LTr, 2013.

ERMIDA URIARTE, Óscar; HERNÁNDEZ ÁLVAREZ, Óscar. Crítica de la Subordinación. In: KURCZYN VILLALOBOS, Patricia; PUIG HERNÁNDEZ, Carlos Alberto (Coords). Estudios jurídicos en homenaje al doctor Néstor de Buen Lozano. México: Instituto de Investigaciones Jurídicas, serie Doctrina Jurídica, n. 148, 2003. p. 269-297. Disponível em: $<$ http://biblio.juridicas.unam.mx/libros/3/109o/16.pdf>. Acesso em: 24 mar. 2018.

FRAGOSO, João Henrique da Rocha. Direito Autoral: da antiguidade à Internet. São Paulo: Quartier Latin, 2009.

GIL, Antônio Carlos. Métodos e Técnicas de Pesquisa Social. 5. ed. São Paulo: Atlas. 2006.

INPI. Instituto Nacional de Propriedade Industrial. Pesquisa em Propriedade Industrial. 2014. 
MINHARRO, Francisco Luciano. A Propriedade Intelectual no Direito do Trabalho. São Paulo: LTr, 2010.

NEWTON, Paulla Christianne da Costa; OLIVEIRA, Flávia de Paiva Medeiros de Oliveira. Flexicurity e Formação: O Investimento em Capital Humano como Elemento Potencializador da Segurança nas Relações Laborais. Revista Dat@venia. v. 3. n. 3. 2010. Disponível em: $<$ http://revista.uepb.edu.br/index.php/datavenia/article/view/1522>. Acesso em: 24 mar. 2018.

NUNES, Claudio Pedrosa; DANTAS, Joama Cristina Almeida. Os Direitos Fundamentais dos Trabalhadores e a Proteção ao Trabalho: Análise da Aplicação do Princípio da Proporcionalidade no Direito Laboral. PRIMA FACIE, João Pessoa, v. 11, n. 20, ano 11, Jan-Jun, 2012, p. 75-92. Disponível em: <http://periodicos.ufpb.br/ojs/index.php/primafacie/article/view/ 10776/8596>. Acesso em: 24 mar. 2018.

PARIS. Convention de Paris pour la Protection de la Propriété Industrielle. 1883. Disponível em: <http://www.wipo.int/treaties/fr/text.jsp?file_id=288516 >. Acesso em: 24 mar. 2018.

PRADO. Elaine Ribeiro do. Gestão e Justiça no Trabalho Inovador: O direito do trabalho na propriedade intelectual. Rio de Janeiro: Lumen Juris, 2011.

RABELLO, João Bosco. Justiça Reconhece a Patente Brasileira do Bina. ESTADÃO. Disponível em: <http://economia.estadao.com.br/noticias/geral,justica-reconhece-a-patente-brasileirado-bina,125963e>. Acesso em: 02 out. 2015. SOUSA, Rosilene Paiva Marinho de. A Informação como Elemento de Regulação dos Institutos Jurídicos da Propriedade Intelectual. 2016. 125 f. Tese (Doutorado em Ciência da Informação) - Universidade Federal da Paraíba, João Pessoa, 2016.

WIPO. The World Intellectual Property Organization. The Concept of Intellectual Property. (WIPO). Disponível em: <http://www.wipo.int/export/sites/www/about-ip/en/iprm/ pdf/ch1.pdf >. Acesso em: 23 mar. 2018.

VIVEIROS, Luciano. Contraprestação Salarial do Empregado na Invenção. São Paulo: LTr, 2010.

ZANIRATO, Silvia Helena; RIBEIRO, Wagner Costa. Conhecimento tradicional e propriedade intelectual nas organizações multilaterais. In: Ambiente \& Sociedade, Campinas, v. X, n. 1, p. 39-55, jan./jun. 2007. 